\title{
Psychological Adjustment of Carers of Children with Type 1 Diabetes Mellitus
}

\author{
Francesca E. Thomson ${ }^{1}$ Philip B. Bergman ${ }^{2,3}$ Margaret Hay ${ }^{4}$ \\ ${ }^{1}$ School of Psychological Sciences, Monash University, Clayton, \\ Victoria, Australia \\ 2Department of Pediatric Endocrinology and Diabetes, Monash \\ Children's Hospital, Clayton, Victoria, Australia \\ ${ }^{3}$ Department of Pediatrics, Monash University Clayton, Victoria, \\ Australia \\ ${ }^{4}$ Monash Institute for Health and Clinical Education, Faculty of \\ Medicine, Nursing and Health Sciences, Monash University, \\ Clayton, Victoria, Australia
}

\begin{abstract}
Address for correspondence Francesca E. Thomson, DPsych(clinical), School of Psychological Sciences, Monash University, 107, 27 Rainforest Walk, Clayton Campus, Wellington Road, Clayton Vic 3800, Australia (e-mail: dacs.carer.wellbeing@gmail.com).
\end{abstract}

J Soc Health Diab 2018;6:80-89.

\section{Introduction}

Prevalence of type 1 diabetes mellitus (T1DM) in Australia continues to rise at a rate of $3.2 \%$ each year, making it the fastest growing chronic illness among Australian children. ${ }^{1}$ Similar trends have also been reported worldwide. ${ }^{2}$ Given the serious and potentially life-threatening immediate and longterm complications associated with extreme blood sugar concentration levels, it is critical that individuals with T1DM maintain blood sugar levels within a safe range. ${ }^{1}$
As T1DM is most commonly diagnosed throughout childhood and adolescence, ${ }^{3}$ self-management of the condition during this developmental stage brings with it potential risk, as young people may have less competence in recognizing and treating symptoms, as well as limited forethought to the longer term medical implications of mismanagement. ${ }^{4}$ As a result, management responsibilities often fall to carers, typically mothers. ${ }^{5,6}$

Caring for a child with T1DM has been described as an overwhelming experience. ${ }^{7}$ Not only do carers have to adjust 
to their child's diagnosis, they are thrown into a state of constant vigilance required to maintain healthy blood glucose levels. $^{7-9}$

It is important to acknowledge that carer adjustment to childhood chronic illness is variable and multidimensional. While some carers are vulnerable to psychological distress, ${ }^{10}$ others demonstrate resilience, and are able to function effectively. ${ }^{11,12}$ Several studies have highlighted the positive intrapersonal and relational aspects associated with caring responsibilities. ${ }^{13,14}$ Theoretical models have been developed in response to this variability, to better understand carer psychological adjustment to childhood chronic illness. This theoretical understanding carries with it important clinical utility, as targeted intervention programs can be developed via identifying contributors to both negative and positive adjustment.

Thompson's Transactional Stress and Coping Model (TTSCM) ${ }^{15}$ explores psychosocial contributors to parent and child psychological adjustment to childhood illness. In developing the model, each factor within adaptational process was included if (1) it was empirically demonstrated to reduce distress, and was therefore (2) considered to be a relevant and tangible target for clinical intervention. The model is detailed in - Fig. 1.

The TTSCM has been applied to carers across a range of pediatric conditions with reported amounts of variance in carer adjustment explained by the model ranging from 30 to $55 \%$. Furthermore, the psychosocial factors of the adaptational process (cognitive processes, methods of coping, and family functioning) have consistently been reported to contribute the most to carer adjustment, with illness and demographic parameters accounting for little variance. ${ }^{15-20}$

Of the psychosocial factors included in the TTSCM, cognitive processes have received most attention within the T1DM carer population. Both general stress associated with everyday tasks and illness specific stress have been found to be associated with increased depression and decreased life satisfaction among carers of children with T1DM. ${ }^{21-25}$ Increased stress appraisal was also found to be associated with post-traumatic stress disorder in mothers of children newly diagnosed with T1DM. ${ }^{26}$ Streisand et $\mathrm{al}^{27}$ also found that parents' efficacy, or confidence in their ability to execute aspects of their child's diabetes management, was significantly related to parenting stress, with lower self-efficacy associated with more frequent stress.

While studies have explored the various coping strategies utilized by carers of children with T1DM, little association has been made between these strategies and carer adjustment. ${ }^{28-30}$ Streisand et $a l,{ }^{25}$ and Jaser et $\mathrm{al}^{31}$ found that carer's subjective perception of coping was related to carer depression and anxiety, with poorer perceptions related to increased psychopathology. In addition, Mellin et al, ${ }^{29}$ discussed strategies used to mediate T1DM stress, including cognitive resturcturing, being proactive with T1DM management, and lifestyle changes (e.g., reducing to part-time work); however, the relationship between these strategies was more qualitatively discussed, rather than empirically analyzed. A recent study by Jaser et $\mathrm{al}^{32}$ reported that among mothers of adolescents with T1DM, disengagement coping strategies were associated with increased symptoms of anxiety and depression, while active coping strategies such as problem solving and acceptance were associated with fewer symptoms. The importance of coping strategies in relation to carer distress has been found in other carer populations including cystic fibrosis ${ }^{33}$ and chronic physical conditions, ${ }^{34}$ highlighting the need for further investigation in T1DM carer populations.

Research on family functioning has typically been conducted in the context of the adjustment of the child with T1DM..$^{35,36}$ Smaldone and Ritholz $z^{37}$ found partner collaboration and shared responsibility in T1DM management were important in building confidence and resilience. Though this focuses on the carer-carer dyad, findings may be generalized to social support within the family context as a whole. Moreira et $\mathrm{a}^{38}$ reported increased family functioning to have a mediating effect on carer distress, with carers who reported increased family cohesion more positively appraising the impact of T1DM on their family. This perceived impact consequently related to increased quality of life and decreased depression, anxiety, and stress.

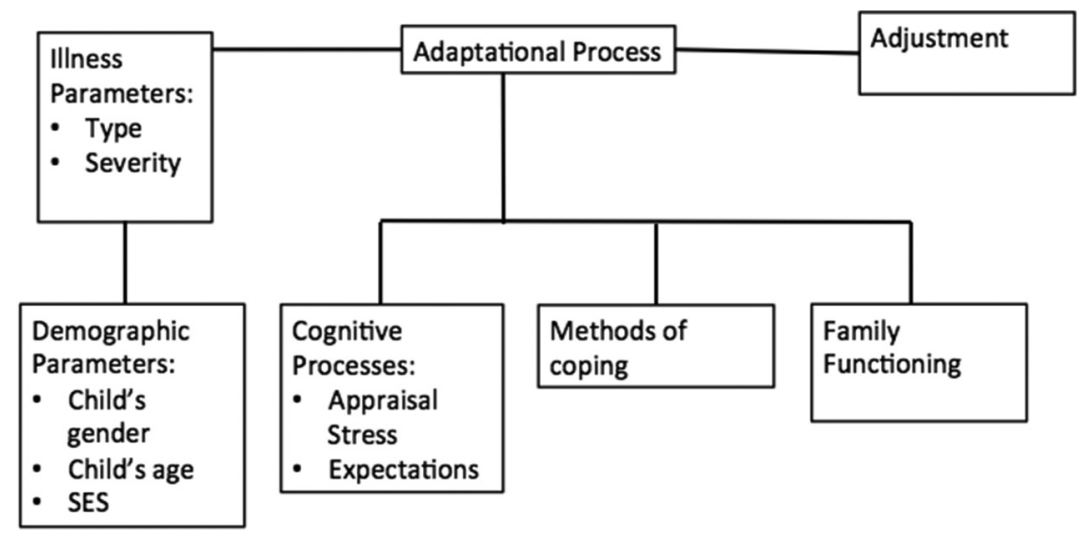

Fig. 1 Thompson's transactional stress and coping model. Adapted from Thompson et al. ${ }^{15}$ SES, socioeconomic status. 
To the authors' knowledge, this is the first research study to employ TTSCM to explore psychological adjustment in carers of children with T1DM. The aim was to provide evidence for the utility of this model within this particular carer population, by exploring factors that contribute to psychological well-being of carers of children with T1DM. Given the efficacy, this model has in delineating carer adjustment in other illness populations; it is intended that current findings be compared with existing research to highlight any communalities or differences of T1DM carer experience.

With sample size constraints and participant convenience (i.e., reducing participant burden via minimizing number of measures) in mind, locus of control was not formally assessed; however, previous research has suggested that the BriefCOPE (utilized in the current study) captures elements of locus of control. ${ }^{39}$ For example, external locus of control was found to be related to passive coping strategies including behavioral disengagement, emotional support, and self-distraction, while internal locus of control was related to active coping, including planning and positive reframing. ${ }^{39}$ This decision was also supported by previous research that has consistently reported locus of control to contribute little to carer adjustment in chronic illness carer populations..$^{15,16,18-20}$

Based on previous research, it was hypothesized that TTSCM would account for a significant amount of variance in T1DM carer adjustment, with psycho-social factors accounting for greater variance in carer adjustment than illness-related factors.

\section{Methods}

\section{Participants}

The sample consisted of 93 carers of children who were attending pediatric diabetes outpatient clinics based across two tertiary metropolitan hospitals and one outer suburban hospital. Participants comprised the sample of a doctoral research study exploring prevalence and predictors of psychological well-being of carers of children with T1DM.

Participants qualified for inclusion if their child had received a diagnosis of T1DM at least 12 months prior to recruitment time. This timeframe was based on research conducted by Northam et $\mathrm{al}^{40}$ who deemed this the minimum time to allow for psychological adjustment to a diabetes diagnosis. English proficiency and access to a computer and Internet connection to complete the online survey were further inclusion criteria.

\section{Procedure}

Potential participants were identified by medical staff, and approached by members of the research team during their child's appointment, who explained the study aims and procedures. Medical staff also promoted the study during their consultations. Given the nature of recruitment, a final response rate could not be calculated. Those who declined to participate were not recorded by clinicians and not contacted. Willing participants were emailed a link to an online questionnaire, for which informed consent was required before gaining access.

\section{Materials}

Illness variables. With carer permission, glycosylated hemoglobin A1c (HbA1c) levels over previous 12 months were collected. The HbA1c is recorded at every clinic visit, which is typically scheduled for approximately once every 3 months. A 12-month HbA1c mean was used as a clinical indicator of the child's metabolic control and measure of T1DM management. Date of T1DM diagnosis and mode of insulin administration were also collected.

Cognitive appraisal. As indicated in - Fig. 1, this domain consists of two key variables, each with two subvariables. Illness-related stress appraisal was measured via the Pediatric Inventory for Parents (PIP). ${ }^{41}$ The PIP consists of 42 items that are categorized into four subscales including communication (e.g., speaking with doctor), emotional functioning (e.g., learning upsetting news), medical care (e.g., helping my child with medical procedures), and role function (trying to attend the needs of other family members). Participants were required to indicate the level of difficulty of disease-related parenting stressors experienced on a 5-point Likert scale ranging from not at all to extremely. A total difficulty score was calculated to represent illness-related parenting stress. For the current study, the Cronbach's $\alpha$ coefficient for difficulty subscale was $\alpha=0.95$.

Typical everyday parenting hassles were measured via the Parenting Stress Index Short Form 4th edition (PSI-4-SF).42 The PSI-4-SF is a 36-item self-report questionnaire that measures stress within the parent-child system. Carers reported the degree to which they agreed with each item (e.g., You feel trapped by your responsibilities as a parent) on a 4-point Likert scale ranging from strongly disagree to strongly agree. A total stress score was then derived, with higher scores indicating higher parental stress. Strong reliability was also reported with a Cronbach's $\alpha$ coefficients in this study, with $\alpha=0.94$.

Self-efficacy was selected to represent the expectancy variable. Participants indicated their self-efficacy on a 10-point Likert scale ranging from I don't believe I can adequately care and manage my child's type 1 diabetes to I strongly believe I can adequately care and manage my child's type 1 diabetes.

Methods of coping. Carer coping was measured using the BriefCOPE, a 28-item self-report questionnaire that assesses 14 conceptually distinct modes of coping, representing both potentially positive and negative coping strategies. ${ }^{43}$ These are active coping, self-distraction, denial, substance use, use of emotional support, behavioral disengagement, emotion-focused coping, use of instrumental support, venting, positive reframing, planning, humor, acceptance, religion, and self-blame. Participants were requested to think of a given situation involving their child that was perceived as particularly distressing, and to indicate for each item their level of engagement of a particular coping statement. Responses were recorded on a 4-point Likert scale ranging from I haven't been doing this at all to I've been doing this a lot, with higher scores indicating a higher level of engagement. The Cronbach's $\alpha$ coefficients for each scale in this study ranged from $\alpha=0.30$ to $\alpha=0.93$. 
Family functioning. The family assessment device (FAD) is a 60 -item self-report questionnaire that measures family functioning. ${ }^{44}$ The FAD consists of a "General Functioning" scale, as well as six specific dimensions taken from the McMaster Model of Family Functioning. Responses for each item were recorded on a 4-point Likert scale ranging from strongly agree to strongly disagree. In the current study, the general functioning score was utilized to represent overall family functioning. Higher scores indicated poorer perception of the family's overall functioning. For the current study, the Cronbach's $\alpha$ coefficient for the General Functioning subscale was $\alpha=0.90$.

Carer adjustment outcome. The 21-item Depression, Anxiety and Stress Scale (DASS21) ${ }^{45}$ was used to measure carer adjustment. The DASS21 consists of three 7-item scales, which measure common depression, anxiety, and stress-related symptoms, as they have occurred over the previous week. Participants were required to indicate the severity of each item on a 4-point Likert scale ranging from did not apply to me at all over the last week to applied to me very much or most of the week. Each response is associated with a score ranging from 0 to 3 , from which a scale score (ranging from 0 to 21) was taken, with higher scores indicating a higher severity of symptoms. The Cronbach's $\alpha$ coefficients for the current sample were depression $\alpha=$ 0.88 , anxiety $\alpha=0.83$, and stress $\alpha=0.88$.

Table 1 Sociodemographic data of carers

\begin{tabular}{|c|c|}
\hline & $\begin{array}{l}\text { Carers of children with T1DM } \\
(N=93)\end{array}$ \\
\hline \multicolumn{2}{|l|}{ Gender } \\
\hline Male & 16 \\
\hline Female & 77 \\
\hline \multicolumn{2}{|l|}{ Relationship status } \\
\hline Single & 5 \\
\hline Defacto/Living with partner & 12 \\
\hline Married & 71 \\
\hline Separated/divorced & 5 \\
\hline \multicolumn{2}{|l|}{ Household income ${ }^{\mathrm{a}}$} \\
\hline Less than 60,000 & 19 \\
\hline $60,001-100,000$ & 36 \\
\hline More than 100,000 & 38 \\
\hline \multicolumn{2}{|l|}{ Educational background } \\
\hline Year 10 or less & 6 \\
\hline Secondary/TAFE & 40 \\
\hline Tertiary & 47 \\
\hline \multicolumn{2}{|l|}{ Place of birth } \\
\hline Australia & 71 \\
\hline Great Britain & 6 \\
\hline Malaysia & 3 \\
\hline Other & $13^{\mathrm{b}}$ \\
\hline Age of carer (mean/standard deviation in years) & $42.92(6.28)$ \\
\hline Number of children under care (mean) & 2.64 \\
\hline Age of children under care (mean/standard deviation in years) & $10.78(3.24)$ \\
\hline \multicolumn{2}{|l|}{ Gender of child } \\
\hline Male & 45 \\
\hline Female & 49 \\
\hline
\end{tabular}

Abbreviations: T1DM, type 1 diabetes mellitus; TAFE, Technical and Further Education.

Note: Four carers had multiple children diagnosed with T1DM, gender for each of these children, and mean age of siblings were included in calculations. Four couples completed the survey independently child gender and age of each couple were recorded only once.

ancome measured in Australian dollars.

bemainder responses consisted of single responses from Canada, China, Colombia, Croatia, Germany, Greece, India, Indonesia, New Zealand, South Africa, Switzerland, United States of America, and Zimbabwe. 


\section{Results}

The demographic data of the participants are presented in - Table 1.

The sample predominantly comprised of educated, middle to upper socioeconomic status (SES), married, and Australian females. Analysis of DASS21 data revealed that 28, 19, and $30 \%$ of the sample scored above the normal cut-off score for depression, anxiety, and stress subscales, respectively.

Medical data indicated that the average duration of T1DM diagnosis was 51.72 months (standard deviation $=38.23$ months). Insulin was administered via continuous subcutaneous insulin infusion (CSII) pump for $29 \%$ of children with T1DM. The CSII pump releases low-dose insulin in regular administrations throughout the day. The remainder of the sample received twice daily injections (30\%), and multiple daily injections (40\%) as modes of insulin administration.

The mean 12-month HbA1c level was 8.46\% (as measured in Diabetes Control and Complications Trial units), which also can be reported as $69 \mathrm{mmol} / \mathrm{mol}$ (as measured in International Federation of Clinical Chemistry units). For the four carers who had multiple children diagnosed with T1DM, sibling mean HbA1c levels were included in analysis. Four couples completed the survey independently; their child HbA1c was recorded only once. With reference to glycemic control guidelines stipulated by the International Society for Pediatric and Adolescent Diabetes, ${ }^{46} 18 \%$ of children had HbA1c levels within the optimal range (below 7.5 DCCT\%), $53 \%$ of children had $\mathrm{HbA} 1 \mathrm{c}$ levels within the suboptimal range (7.5-9 DCCT\%), and $29 \%$ of children had HbA1c levels within the high-risk range (above 9 DCCT\%).

Information on those who declined participation was not collected; however, to gauge representativeness of T1DM sample, illness and management data were compared with clinic data sourced from the two metropolitan outpatient clinics. These clinical data revealed that the 257 patients (aged 16 or under, with T1DM diagnosis for minimum 12 months) attending clinics taken at the time of recruitment, had a mean HbA1c level of $8.58 \%$. In addition, $35 \%$ were receiving multiple daily injections, $24 \%$ were receiving twice daily injections, and $41 \%$ were utilizing CSII pump.

\section{Factor Structure of Coping Strategies}

The BriefCOPE underwent preliminary analysis to identify component structure to reduce the number of independent variables entered in subsequent analysis. A principal components analysis (PCA) was conducted using a wider sample of 177 carers collected as part of the doctoral research, 93 of which were the participants of the current study, and the remainder a comparison sample, to assess how a carer population perceived items of the BriefCOPE. The factorability of the BriefCOPE ${ }^{43}$ variables within this larger sample was assessed using the Kaiser-Meyer-Olkin measure of sampling adequacy $(\mathrm{KMO}=0.78)$, indicating appropriate sampling adequacy (values of $\geq 0.6$ are required for factor analysis ${ }^{47}$ ).

The factor structure of the BriefCOPE ${ }^{43}$ was identified by replicating Carver's PCA, with oblique rotation on the 28 items. Seven generated components had eigenvalues greater than one; however, the scree plot, used to identify the point at which the amount of variance accounted for by each additional factor is relatively low, indicated a three-point solution below the elbow. Moreover, these three components accounted for $47.6 \%$ of the total variance, and included all 14 of Carver's subscales. A forced three component PCA was subsequently performed. The clusters of item statements making up each of the three components underwent objective qualitative examination by three independent observers to produce descriptive labels for each of the components. Two complex items (i.e., items with component loading coefficients of above 0.40 on more than one factor), from the instrumental support and self-blame subscales were removed as per recommended protocol by Tabachnick and Fidell. ${ }^{47}$ Component one, containing 10 items, was labeled proactive coping. Component two, also containing 10 items, was labeled avoidant coping. A third component containing five items was labeled reframing and reflecting coping. All three components produced adequate reliability, with Cronbach's $\alpha$ coefficients for component one $\alpha=0.85$, component two $\alpha=0.82$, and component three $\alpha=0.71$. The component loading coefficients for the three derived components are shown in - Table 2. A score for each of the coping components was then calculated by summing the scores for each subscale contributing to the component, for use in canonical correlation analysis.

\section{Canonical Correlation}

Canonical correlation measures the strength of the relationship between sets of independent and dependent variables known as variates. In addition, it also measures strength of relationship each independent variable (which contributes to the independent variate) has with the dependent variate. ${ }^{48}$ In the current study, the independent variate was illness and psychosocial factors of the TTCM and was made up of the following independent variables: duration of T1DM diagnosis, HbA1c levels, illness and general parenting stress appraisal, illness self-efficacy, coping strategies, and family functioning. The dependent variate was carer psychological adjustment, and included the following dependent variables: depression, anxiety, and stress.

To improve linearity of the relationship between variables and normality of their distributions, transformations were applied to illness-related stress appraisal, proactive coping, and reframing/reflecting coping scores. Seventeen univariate outliers were found among three of the independent variables, and the three dependent variables. To reduce the impact of these outliers, raw scores were changed on the offending variables to one unit larger than the next most extreme score in the distribution. ${ }^{48}$ No multivariate outliers were identified at $p<0.001$, and there was no missing data. Assumptions regarding within-set multicollinearity were met. In this analysis, there are nine metric-independent variables and three metric dependent variables. With 93 participants, this meets the recommended 10 observations per independent variable. ${ }^{48}$ 
Table 2 Forced 3 component PCA with oblique rotation on Brief COPE items

\begin{tabular}{|c|c|c|c|}
\hline Variable (original subscale) & $\begin{array}{l}\text { Component } 1 \\
\text { Proactive }\end{array}$ & $\begin{array}{l}\text { Component } 2 \\
\text { Avoidant }\end{array}$ & $\begin{array}{l}\text { Component } 3 \\
\text { Reframing/reflecting }\end{array}$ \\
\hline $\begin{array}{l}\text { I've been taking action to try to make the } \\
\text { situation better (active coping) }\end{array}$ & 0.82 & & \\
\hline $\begin{array}{l}\text { I've been concentrating my efforts on doing } \\
\text { something about the situation I'm in (active } \\
\text { coping) }\end{array}$ & 0.77 & & \\
\hline $\begin{array}{l}\text { I've been thinking hard about what steps to } \\
\text { take (planning) }\end{array}$ & 0.74 & & \\
\hline $\begin{array}{l}\text { I've been trying to come up with a strategy } \\
\text { about what to do (planning) }\end{array}$ & 0.66 & & \\
\hline $\begin{array}{l}\text { I've been getting emotional support from } \\
\text { others (use of emotional support) }\end{array}$ & 0.64 & & \\
\hline $\begin{array}{l}\text { I've been accepting the reality of the fact that } \\
\text { is has happened (acceptance) }\end{array}$ & 0.62 & & \\
\hline $\begin{array}{l}\text { I've been getting comfort and understanding } \\
\text { from someone (use of emotional support) }\end{array}$ & 0.61 & & \\
\hline $\begin{array}{l}\text { I've been trying to see it in a different light, } \\
\text { to make it seem more positive (positive } \\
\text { reframing) }\end{array}$ & 0.54 & & \\
\hline I've been learning to live with it (acceptance) & 0.50 & & \\
\hline $\begin{array}{l}\text { I've been expressing my negative feelings } \\
\text { (venting) }\end{array}$ & 0.41 & & \\
\hline $\begin{array}{l}\text { I've been giving up trying to deal with it (be- } \\
\text { havioral disengagement) }\end{array}$ & & 0.75 & \\
\hline I've been criticizing myself (self-blame) & & 0.73 & \\
\hline $\begin{array}{l}\text { I've been using alcohol or other drugs to help } \\
\text { get me through it (substance abuse) }\end{array}$ & & 0.72 & \\
\hline $\begin{array}{l}\text { I've been giving up the attempt to cope (be- } \\
\text { havioral disengagement) }\end{array}$ & & 0.70 & \\
\hline $\begin{array}{l}\text { I've been using alcohol or other drugs to make } \\
\text { myself feel better (substance abuse) }\end{array}$ & & 0.63 & \\
\hline $\begin{array}{l}\text { I've been refusing to believe that it has hap- } \\
\text { pened (denial) }\end{array}$ & & 0.61 & \\
\hline $\begin{array}{l}\text { I have been turning to work or other activities } \\
\text { to take my mind off things (self-distraction) }\end{array}$ & & 0.56 & \\
\hline $\begin{array}{l}\text { I've been saying things to let my unpleasant } \\
\text { feelings escape (venting) }\end{array}$ & & 0.49 & \\
\hline $\begin{array}{l}\text { I've been doing something to think about it } \\
\text { less, such as going to movies, watching TV, } \\
\text { reading, daydreaming, sleeping or shopping } \\
\text { (self-distraction) }\end{array}$ & & 0.48 & \\
\hline I've been making fun of the situation (humor) & & 0.42 & \\
\hline $\begin{array}{l}\text { I've been trying to find comfort in my religion } \\
\text { or spiritual beliefs (religion) }\end{array}$ & & & -0.65 \\
\hline I've been praying or meditation (religion) & & & -0.65 \\
\hline $\begin{array}{l}\text { I've been looking for something good in what } \\
\text { is happening (positive reframing) }\end{array}$ & & & -0.59 \\
\hline I've been making jokes about it (humor) & & & -0.51 \\
\hline $\begin{array}{l}\text { I've been trying to get advice or help from } \\
\text { other people about what I do (use of instru- } \\
\text { mental support) }\end{array}$ & & & -0.51 \\
\hline
\end{tabular}

Abbreviation: PCA, principal components analysis. 
As the dependent variable set only has three indicators, three canonical functions were derived. - Table 3 details the canonical correlation analysis, with associated multivariate tests of significance.

As can be seen in - Table 3, only function 1 was statistically significant. In addition, multivariate tests of functions were undertaken simultaneously, including the Wilks' lambda, Pillai's criterion, Hotelling's trace, and Roy's grc. All of these multivariate test statistics indicated that the first canonical function, taken collectively, was statistically significant at a 0.001 level. The second and third canonical functions failed to achieve significance at a 0.05 level.

The first function had a conical correlation of 0.75 . While there are no generally agreed upon guidelines regarding what constitutes an acceptable size of canonical correlation to meet practical significance, Hair et $\mathrm{al}^{48}$ argue that it is logical that the guidelines for loadings in factor analysis can be used, as canonical correlations refer to the variance explained in the canonical variates, not the original separate variables. Therefore, based on these guidelines, all canonical coefficients of 0.3 and above can be deemed as having practical significance. ${ }^{48}$ Rotation was not performed as there needs to be at least two significant conical functions and as mentioned above, only one significant function was found.

The Stewart-Love redundancy index ${ }^{49}$ represents the amount of variance in one set of variables that can be explained by the variables in the other set. Redundancy indices can be calculated for both the dependent and independent variable sets; however, typically, the index extracted from the dependent variable set is of most importance, as it provides a more realistic measure of the predictive ability of the canonical relationship. ${ }^{46}$ Redundancy indices are thought to be the least-biased measure of variance and is comparable to the $R^{2}$ statistic in multiple regression. The redundancy index for the first canonical function is presented in - Table 4.

As can be seen in - Table 4, the redundancy index indicates $43 \%$ of the variance of carer adjustment can be explained by the independent variable set. While again, there is no agreed upon minimum acceptable redundancy index to justify further interpretation of the canonical function, the redundancy index is above the cut-off point of 0.3 (deemed an appropriate criterion as discussed above); therefore, further interpretation of cross loadings was undertaken.

Canonical cross-loadings represent how each independent or dependent variable correlates to the opposite canonical variate. Hair et $\mathrm{al}^{48}$ argue that cross-loadings are the most direct measure or variable-variate relationships. - Table $\mathbf{5}$ includes the cross-loadings for the independent and dependent variables.

Squaring the dependent variable canonical cross-loadings presented in - Table 5 indicated that $51.84 \%$ of the variance in DASS21 depression subscale scores, 30.25\% of DASS21 anxiety subscale scores, and $50.41 \%$ of stress subscale scores were explained by the independent variate. An investigation of the cross-loadings of the independent variables ( - Table 5 ) confirmed that illness related and general stress appraisal and avoidant coping made the strongest predictive contributions to the dependent variate, all producing cross-loadings

Table 3 Canonical correlation analysis relating carer psychosocial factors to care psychological adjustment

\begin{tabular}{|c|c|c|c|c|c|}
\hline \multicolumn{6}{|c|}{ Measures of overall model fit for canonical correlation analysis } \\
\hline Canonical function & Canonical correlation & \multicolumn{2}{|c|}{ Canonical $R^{2}$} & F Statistics & Probability \\
\hline 1 & 0.75 & \multicolumn{2}{|l|}{0.57} & 3.58 & $<0.0001$ \\
\hline 2 & 0.31 & \multicolumn{2}{|l|}{0.10} & 0.83 & 0.65 \\
\hline 3 & 0.23 & \multicolumn{2}{|l|}{0.05} & 0.68 & 0.69 \\
\hline \multicolumn{6}{|c|}{ Multivariate tests of significance } \\
\hline Statistic & \multicolumn{2}{|l|}{ Value } & \multicolumn{2}{|c|}{ Approximate $F$ Statistics } & Probability \\
\hline Wilks' lambda & 0.37 & & \multicolumn{2}{|c|}{3.58} & $<0.0001$ \\
\hline Pillai's trace & 0.72 & & \multicolumn{2}{|l|}{2.90} & $<0.0001$ \\
\hline Hotelling's trace & 1.48 & & \multicolumn{2}{|l|}{4.38} & $<0.0001$ \\
\hline Roy's grc & \multicolumn{2}{|l|}{0.57} & & \\
\hline
\end{tabular}

Table 4 Redundancy index for dependent variate

\begin{tabular}{|c|c|c|c|c|c|}
\hline Variates/Variables & $\begin{array}{l}\text { Canonical } \\
\text { loading }\end{array}$ & $\begin{array}{l}\text { Canonical loading } \\
\text { squared }\end{array}$ & $\begin{array}{l}\text { Average loading } \\
\text { squared }\end{array}$ & Canonical $R^{2}$ & $\begin{array}{l}\text { Redundancy } \\
\text { index }\end{array}$ \\
\hline \multicolumn{6}{|l|}{ Dependent variables } \\
\hline DASS21 depression subscale score & -0.95 & 0.91 & & & \\
\hline DASS21 anxiety subscale score & -0.74 & 0.54 & & & \\
\hline DASS21 stress subscale score & -0.94 & 0.88 & & & \\
\hline Dependent variates & & 2.33 & $\cong 0.78$ & 0.55 & 0.43 \\
\hline
\end{tabular}

Abbreviation: DASS21, 21-item Depression, Anxiety and Stress Scale. 
Table 5 Canonical cross-loadings for the independent and dependent variables

\begin{tabular}{|c|c|}
\hline Variables & $\begin{array}{l}\text { Canonical } \\
\text { Cross-Loadings }\end{array}$ \\
\hline \multicolumn{2}{|l|}{ Independent variables } \\
\hline HbA1c levels & -0.05 \\
\hline Duration of diagnosis & 0.07 \\
\hline Illness-related stress appraisal & -0.60 \\
\hline General parenting stress appraisal & -0.56 \\
\hline Diabetes self-efficacy & 0.23 \\
\hline Proactive coping & 0.20 \\
\hline Avoidant coping & -0.54 \\
\hline Reframing/Reflecting coping & 0.19 \\
\hline Family functioning & -0.29 \\
\hline \multicolumn{2}{|l|}{ Dependent variables } \\
\hline DASS21 depression subscale score & -0.72 \\
\hline DASS21 anxiety subscale score & -0.55 \\
\hline DASS21 stress subscale score & -0.71 \\
\hline
\end{tabular}

Abbreviation: DASS21, 21-item Depression, Anxiety and Stress Scale.

of above 0.3. Family functioning also made a strong contribution, as it approached practical significance. The negative relationship of these cross-loadings indicates that increased illness and general stress appraisal and avoidant coping are associated with poorer psychological adjustment.

\section{Discussion}

The current study aimed to explore the illness and psychosocial factors that contribute to psychological adjustment of carers of children with T1DM. In addition, it sought to assess the utility of TTSCM ${ }^{15}$ in the T1DM carer population, as previous research has consistently supported its efficacy in identifying factors associated with maternal adjustment among other chronic illness populations. It was hypothesized that the model would account for a significant amount of variance in carer adjustment; and that the psychosocial factors of the adaptational process ( - Fig. 1) would be more strongly related to carer adjustment than illness parameters.

Results indicated that the model accounted for nearly half (43\%) the variance in carer adjustment, thus supporting the first hypothesis. As this study was the first to employ TTSCM to explore adjustment of carers of children with T1DM, this finding supports the utility of the model in this population, contributing to the growing amount of evidence from previous research in other pediatric chronic conditions. ${ }^{15-20}$

Furthermore, findings also supported the hypothesized importance of adaptational process in explaining carer adjustment. Illness-related information, which included HbA1c levels and duration of diagnosis, made the weakest contributions to carer adjustment, as indicated by very low cross-loadings. Again, this finding was consistent with previous TTSCM research. Illness parameters did not significantly predict adjustment among mothers of children and adolescents with sickle cell disease, cystic fibrosis, and congenital heart disease. ${ }^{15,17,19,20}$

With reference to the adaptational process, the current study found stress appraisal, including both illness related and general parenting stress, as well as avoidant coping to be strongly negatively related to carer adjustment. While it would be reasonable to expect general parenting stress to be influenced by caring for a child with T1DM, there was only $23 \%$ of shared variance in carers' appraisals of general parenting stress and illness-related parenting stress. In relation to stress appraisal, previous research is somewhat contrasting. For example, the current study had similar findings reported by Thompson et $\mathrm{al}^{20}$ who found both sources of stress appraisal to be significant contributors to maternal adjustment. However, Thompson et al $^{15,19}$ reported that only increased general stress predicted poor adjustment, and illness-related stress had no significant relationship. This difference may reflect other possible illness or carer-related variables that might influence the relationship between stress appraisal and adjustment. Though this exploration that was beyond the scope of the current study, it is recommended for future research.

In relation to coping, previous research has consistently reported a negative relationship between what is often referred to as palliative coping (which included items reflecting emotion-focused, avoidance, wishful thinking, and self-blame factors) and carer adjustment. ${ }^{15,17,19,20}$ Interestingly, this growing evidence demonstrates how avoidant coping appears to have a stronger relationship with negative adjustment, than adaptive coping (which often reflects problem-focused, cognitive restructuring, seeking information, and seeking social support factors) has with positive adjustment.

Compared with stress appraisal and avoidant coping, family functioning demonstrated a weaker relationship with carer adjustment. In saying this, current findings suggested family functioning approached practical significance. Similar to stress appraisal, the relationship between family functioning and adjustment is unclear. For example, Thompson et al $^{19}$ and Davis et al $^{17}$ reported family functioning accounted for only 3 and $1 \%$ of the variance in carer adjustment, respectively, in carers of children with sickle cell disease and congenital heart disease. Conversely, Thompson et al, ${ }^{15}$ Thompson et $\mathrm{al}^{20}$ and Sloper $^{18}$ reported family supportiveness to be a significant contributor to adjustment in cystic fibrosis, sickle cell disease, and maternal cancer populations. The reasons behind these contradictive findings are unclear. Davis et $\mathrm{al}^{17}$ argued that culture could influence how family functioning is conceptualized, as one-third of their sample consisted of African American mothers (the remainder of sample were Caucasian). However, the sample of Thompson et $\mathrm{al}^{20}$ study, which as mentioned reported contrasting findings, consisted entirely of African American mothers. Again, these differences highlight the need for future research to explore this seemingly complex relationship.

The final variable in TTSCM entered into the analysis was diabetes self-efficacy. Similar to family functioning, results 
indicated that self-efficacy contributed little to carer adjustment. This is consistent with findings from Davis et $\mathrm{al}^{17}$; however, Thompson et $\mathrm{al}^{15}$ reported self-efficacy to be negatively related to anxiety. As the current study and Davis et a ${ }^{17}$ conceptualized adjustment as a combination of psychological symptom dimensions, it could be argued that self-efficacy may only have a significant relationship with anxiety, since a carer's increased confidence in their ability to manage their child's illness would reasonably reduce anxiety.

As previously mentioned, to the authors' knowledge, this was the first empirical study to implement TTSCM to explore psychological adjustment of carers of children with T1DM. While the nature of recruitment prevented data collection of participants who declined participation, medical sample data were compared with clinic data, indicating the sample was representative of the target carer population. In saying this, however, the carer sample was predominantly made of educated, middle to upper SES, married, Australian females. While this demographic profile is common in reported carer research, ${ }^{10}$ generalizability of findings may be limited. Additionally, although scales in this study were psychometrically sound, they, as with all self-report measures, remain vulnerable to subject bias. Given the cross-sectional design, the relationships reported between the adaptational process and adjustment cannot definitively be deemed as causal. Future research should take the next step of exploring longitudinal stability of these relationships over time. Finally, while the sample size met the minimum requirement for all analyses conducted, larger numbers would allow for additional variables to be explored, which may explain greater carer adjustment.

Despite these limitations, important theoretical and practical implications can be drawn from the current findings. First, findings highlight the importance of incorporating theory to examine carer adjustment to pediatric chronic illness. Second, and perhaps most notably, findings have highlighted tangible areas of psychological intervention.

The present study provided a unique contribution toward understanding psychological adjustment of carers of children with T1DM. Results not only supported the application of TTSCM in this population but also highlighted stress appraisal and copings strategies as focal points for psychological intervention. Carer adjustment to childhood chronic illness remains an under-researched area, and contradicting findings in relation to the TTSCM adaptational process highlight the need for further formulation. However, the findings of this study might inspire future research to further enrich our understanding of the psychological adjustment of carers of children with T1DM and also other pediatric chronic illness conditions.

\section{Paper Presentation}

Prior to publication this article was presented via poster at VIII Ibero American Congress of Clinical and Health Psychology.

\section{Funding}

None.

\section{Conflict of Interest}

None.

\section{Acknowledgments}

The authors wish to thank the carers involved in the study, as well as staff of Department of Pediatric Endocrinology and Diabetes, Monash Children's Hospital, and Department of Pediatrics, Peninsular Health. In particular, the authors extend thanks and appreciation of assistance from Dr Justin Brown, Dr Cecelia GarciaRudaz, Dr Peter Sims, and Dr Mary White.

\section{References}

1 Juvenile Diabetes Research Foundation. Living with type 1 diabetes, http://www.jdrf.org.au; 2015. Accessed May 10, 2016

2 Dabelea D. The accelerating epidemic of childhood diabetes. Lancet 2009;373(9680):1999-2000

3 Gale EA. Type 1 diabetes in the young: the harvest of sorrow goes on. Diabetologia 2005;48(8):1435-1438

4 American Diabetes Association. Standards of medical care in diabetes-2009. Diabetes Care 2009;32(Suppl 1):S13-S61

5 Kovacs M, lyengar S, Goldston D, Obrosky DS, Stewart J, Marsh J. Psychological functioning among mothers of children with insulin-dependent diabetes mellitus: a longitudinal study. J Consult Clin Psychol 1990;58(2):189-195

6 Mitchell SJ, Hilliard ME, Mednick L, Henderson C, Cogen FR, Streisand R. Stress among fathers of young children with type 1 diabetes. Fam Syst Health 2009;27(4):314-324

7 Clarke WL, Gonder-Frederick A, Snyder AL, Cox DJ. Maternal fear of hypoglycemia in their children with insulin dependent diabetes mellitus. J Pediatr Endocrinol Metab 1998;11 (Suppl 1):189-194

8 Marrero DG, Guare JC, Vandagriff JL, Fineberg NS. Fear of hypoglycemia in the parents of children and adolescents with diabetes: maladaptive or healthy response? Diabetes Educ 1997;23(3):281-286

9 Sullivan-Bolyai S, Deatrick J, Gruppuso P, Tamborlane W, Grey M. Constant vigilance: mothers' work parenting young children with type 1 diabetes. J Pediatr Nurs 2003;18(1):21-29

10 Whittemore R, Jaser S, Chao A, Jang M, Grey M. Psychological experience of parents of children with type 1 diabetes: a systematic mixed-studies review. Diabetes Educ 2012;38(4):562-579

11 Caffrey-Craig B. Childhood asthma: a stress-related illness? More myth than fact. Ir J Psychol 2005;26:149-159

12 Markson S, Fiese BH. Family rituals as a protective factor for children with asthma. J Pediatr Psychol 2000;25(7):471-480

13 Lundh U. Family carers. 3: coping strategies among family carers in Sweden. Br J Nurs 1999;8(11):735-740

14 Nolan M, Grant G, Keady J. Understanding Family Care: A Multidimensional Model of Caring and Coping. Buckingha Open University Press; 1996

15 Thompson RJ Jr, Gustafson KE, Hamlett KW, Spock A. Stress, coping, and family functioning in the psychological adjustment of mothers of children and adolescents with cystic fibrosis. J Pediatr Psychol 1992;17(5):573-585

16 Bachanas PJ, Kullgren KA, Schwartz KS, McDaniel JS, Smith J, Nesheim S. Psychological adjustment in caregivers of school-age children infected with HIV: stress, coping, and family factors. J Pediatr Psychol 2001;26(6):331-342

17 Davis CC, Brown RT, Bakeman R, Campbell R. Psychological adaptation and adjustment of mothers of children with congenital heart disease: stress, coping, and family functioning. J Pediatr Psychol 1998;23(4):219-228 
18 Sloper P. Predictors of distress in parents of children with cancer: a prospective study.J Pediatr Psychol 2000;25(2):79-91

19 Thompson RJ Jr, Gil KM, Burbach DJ, Keith BR, Kinney TR. Psychological adjustment of mothers of children and adolescents with sickle cell disease: the role of stress, coping methods, and family functioning. J Pediatr Psychol 1993;18(5):549-559

20 Thompson RJ Jr, Gustafson KE, Hamlett KW, Spock A. Psychological adjustment of children with cystic fibrosis: the role of child cognitive processes and maternal adjustment. J Pediatr Psychol 1992b;17(6):741-755

21 Helgeson VS, Becker D, Escobar O, Siminerio L. Families with children with diabetes: implications of parent stress for parent and child health. J Pediatr Psychol 2012;37(4):467-478

22 Patton SR, Dolan LM, Henry R, Powers SW. Parental fear of hypoglycemia: young children treated with continuous subcutaneous insulin infusion. Pediatr Diabetes 2007;8(6):362-368

23 Rumburg TM, Lord JH, Savin KL, Jaser SS. Maternal diabetes distress is linked to maternal depressive symptoms and adolescents' glycemic control. Paediatr Diabetes 2017;18:67-70

24 Streisand R, Mackey ER, Elliot BM, et al. Parental anxiety and depression associated with caring for a child newly diagnosed with type 1 diabetes: opportunities for education and counseling. Patient Educ Couns 2008;73(2):333-338

25 Streisand R, Mackey ER, Herge W. Associations of parent coping, stress, and well-being in mothers of children with diabetes: examination of data from a national sample. Matern Child Health J 2010;14(4):612-617

26 Horsch A, McManus F, Kennedy P, Edge J. Anxiety, depressive, and posttraumatic stress symptoms in mothers of children with type 1 diabetes. J Trauma Stress 2007;20(5):881-891

27 Streisand R, Swift E, Wickmark T, Chen R, Holmes CS. Pediatric parenting stress among parents of children with type 1 diabetes: the role of self-efficacy, responsibility, and fear. J Pediatr Psychol 2005;30(6):513-521

28 Azar R, Solomon CR. Coping strategies of parents facing child diabetes mellitus. J Pediatr Nurs 2001;16(6):418-428

29 Mellin AE, Neumark-Sztainer D, Patterson JM. Parenting adolescent girls with type 1 diabetes: parents' perspectives. J Pediatr Psychol 2004;29(3):221-230

30 Seppänen SM, Kyngäs HA, Nikkonen MJ. Coping and social support of parents with a diabetic child. Nurs Health Sci 1999;1(1):63-70

31 Jaser SS, Whittemore R, Ambrosino JM, Lindemann E, Grey M. Coping and psychosocial adjustment in mothers of young children with Type 1 diabetes. Child Health 2009; 38(2): 92-106.

32 Jaser SS, Linsky R, Grey M. Coping and psychological distress in mothers of adolescents with type 1 diabetes. Matern Child Health J 2014;18(1):101-108

33 Sheehan J, Hiscock H, Massie J, Jaffe A, Hay M. Caregiver coping, mental health and child problem behaviours in cystic fibrosis: a cross-sectional study. Int J Behav Med 2014;21(2):211-220
34 Churchill SS, Villareale NL, Monaghan TA, Sharp VL, Kieckhefer GM. Parents of children with special health care needs who have better coping skills have fewer depressive symptoms. Matern Child Health J 2010;14(1):47-57

35 Drotar D. Relating parent and family functioning to the psychological adjustment of children with chronic health conditions: what have we learned? What do we need to know? J Pediatr Psychol 1997;22(2):149-165

36 Leonard BJ, Jang YP, Savik K, Plumbo MA. Adolescents with type 1 diabetes: family functioning and metabolic control. J Fam Nurs 2005;11(2):102-121

37 Smaldone A, Ritholz MD. Perceptions of parenting children with type 1 diabetes diagnosed in early childhood. J Pediatr Health Care 2011;25(2):87-95

38 Moreira H, Frontini R, Bullinger M, Canavarro MC. Caring for a child with type 1 diabetes: links between family cohesion, perceived impact, and parental adjustment. J Fam Psychol 2013;27(5):731-742

39 Masters KS, Wallston KA. Canonical correlation reveals important relations between health locus of control, coping, affect and values. J Health Psychol 2005;10(5):719-731

40 Northam E, Anderson P, Adler R, Werther G, Warne G. Psychosocial and family functioning in children with insulin-dependent diabetes at diagnosis and one year later. J Pediatr Psychol 1996;21(5):699-717

41 Streisand R, Braniecki S, Tercyak KP, Kazak AE. Childhood illness-related parenting stress: the pediatric inventory for parents. J Pediatr Psychol 2001;26(3):155-162

42 Abidin RR. Manual for the Parenting Stress Index. Odessa, FL: Psychological Assessment Resources; 1995

43 Carver CS. You want to measure coping but your protocol's too long: consider the brief COPE. Int J Behav Med 1997; 4(1):92-100

44 Epstein NB, Baldwin LM, Bishop DS. The McMaster Family Assessment Device. J Marital Fam Ther 1983;9:171-180

45 Lovibond SH, Lovibond PF. Manual for the Depression Anxiety Stress Scales. 2nd edition. Sydney: Psychology Foundation; 1995

46 Rewers MJ, Pillay K, de Beaufort C, et al; International Society for Pediatric and Adolescent Diabetes. ISPAD Clinical Practice Consensus Guidelines 2014. Assessment and monitoring of glycemic control in children and adolescents with diabetes. Pediatr Diabetes 2014;15(Suppl 20):102-114

47 Tabachnick BG, Fidell LS. Using Multivariate Statistics, 5th edition. Needham Height, MA: Allyn \& Bacon; 2007

48 Hair JF, Black WC, Babin BJ, Anderson RE, Tatham RL. Multivariate Data Analysis, 7th ed. New York, NY: Pearson; 2010

49 Stewart D, Love W. A general canonical correlation index. Psychol Bull 1968;70(3):160-163 